Neurosurg Focus 11 (1):Article 1, 2001, Click here to return to Table of Contents

\title{
Definition of the adult Chiari malformation: a brief historical overview
}

\author{
GHaSsan K. BeJJani, M.D. \\ Department of Neurosurgery, University of Pittsburgh Medical Center, Pittsburgh, Pennsylvania
}

\begin{abstract}
With the widespread use of newer neuroimaging techniques and modalities, significant tonsillar herniation is being diagnosed in more than $0.5 \%$ of patients, some of whom are asymptomatic. This puts the definition of the adult Chiari malformation to the test. The author provides a historical review of the evolution of the definition of the adult Chiari malformation in the neurosurgery, radiology, and pathology literature.
\end{abstract}

\begin{abstract}
KEY WORDS • adult Chiari malformation • Chiari I malformation • tonsillar ectopia • syringomyelia
\end{abstract}

There is confusion in the literature regarding the concept of Chiari I malformation or adult Chiari malformation. Recent advances in neuroimaging modalities and their widespread use has led to an increase in the number of patients with radiological evidence of tonsillar herniation, some of whom are asymptomatic, raising questions as to its true clinical relevance. This is especially true because its incidence has been found to be between $0.56 \%{ }^{37}$ and $0.77 \%{ }^{65}$ on MR imaging studies, as well as $0.62 \%$ in brain dissection studies. ${ }^{41}$ With that in mind, we attempted to review the various historical steps that marked the evolution of the definition of adult Chiari malformation.

\section{CHIARI'S INITIAL REPORT}

The entire concept of these malformations emerged toward the end of the 19th century from Chiari's initial descriptions of "alterations in the cerebellum resulting from cerebral hydrocephalus."22,30

Hans Chiari (1851-1916) was born in Vienna, Austria. His father was the famous gynecologist J. B. V. L. Chiari ${ }^{80}$ and his brother was the rhinolaryngologist Ottokar Chiari. ${ }^{55} \mathrm{He}$ graduated from medical school in 1875 and became assistant to the Austrian pathologist Karl Rokitansky at the Institute of Pathology in Vienna. Chiari himself became professor of Pathology in Prague, Czechoslovakia, in 1882, and in Strasbourg, France, in 1906. His initial work on what would become known as Chiari malformation was published in Deutsche Medizinische Wochenscriff in 1891 and entitled "Concerning alterations in the cerebellum resulting from cerebral hydrocephalus." 22

\footnotetext{
Abbreviations used in this paper: $\mathrm{CSF}=$ cerebrospinal fluid; $\mathrm{ICP}=$ intracranial pressure; $\mathrm{MR}=$ magnetic resonance .
}

As the title suggests, his goal was to describe "the consecutive changes established in the region of the cerebellum by cerebral hydrocephalus." The first type he described, which came to be known as Chiari Type I, was characterized by "elongation of the tonsils and medial divisions of the inferior lobules of the cerebellum into cone shaped projections which accompany the medulla oblongata into the spinal canal" (Fig. 1). These features were demonstrated in a "relatively large percentage of cases of chronic congenital hydrocephalus but never without hydrocephalus or in cases of acute or later-developing hydrocephalus .... The elongated portions of the cerebellum can show either normal structure, fibrosis or softening....and...extend nearly to the top of the atlas, however in many cases to the undersurface of the axis." Although no clinical symptoms were reported, he speculated that "it is not unlikely that bulbar symptoms could be caused." The case he described was that of a 17-year-old young woman who died of typhoid fever. She suffered from hydrocephalus but "no symptoms referable to the cerebellum or medulla." This was probably the first case of Chiari I malformation to be described.

Five years later, in a new study, ${ }^{21}$ Chiari described 14 cases with Type I changes (Fig. 2). The grade of hydrocephalus was not related to the severity of the craniospinal changes. He supposed that an additional mechanism played a role in this condition-namely, insufficient bone growth and insufficient enlargement of skull parts resulting in increased ICP.

He described other malformations that are beyond the scope of this presentation; however, we will discuss briefly the origin of the nomenclature "Arnold-Chiari malformation" because there was considerable confusion initially when describing the first two types. In the Type II 


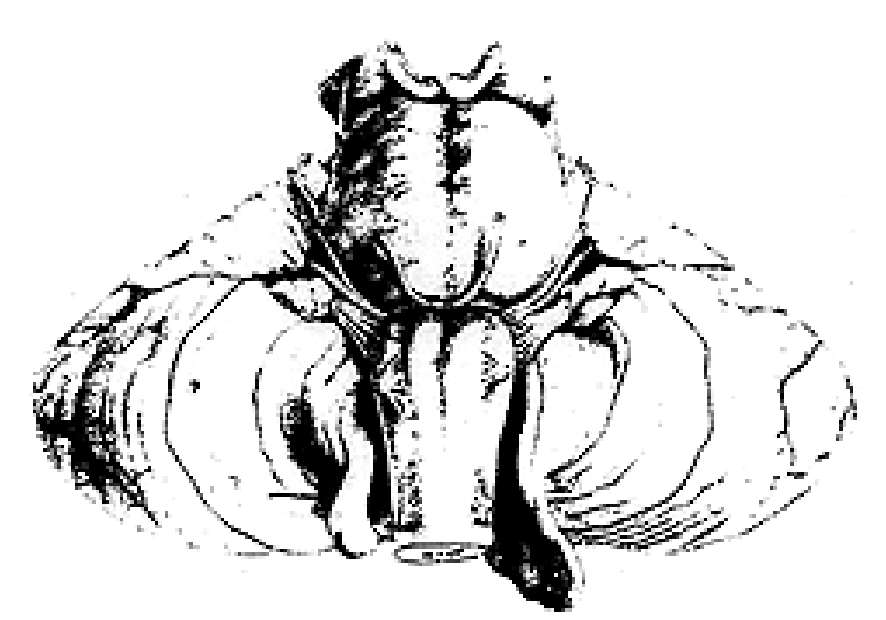

Fig. 1. Illustration of Chiari I malformation in his 1896 publication, showing the tonsillar ectopia. Used with permission from Koehler PJ: Chiari's description of cerebellar ectopy (1891). J. Neurosurg 75:823-826, 1991.

anomaly that Chiari described, there were displacements of parts of the inferior vermis, pons, and medulla oblongata as well as elongation of the fourth ventricle into the spinal canal. In the concluding remarks of his 1896 publication, he mentioned a few authors who had already published on this subject, including Cleland and Arnold. In 1883 Cleland $^{24}$ reported the case of an infant with spina bifida and hydrocephalus similar to Chiari's type II cases. In 1894 Arnold $^{7}$ described an infant with spina bifida in whom there was, elongation of the hindpart of the cerebellum, covering the fourth ventricle and extending into the cervical canal. The observations of these authors, however, were incidental compared with Chiari's thorough study of the malformation. Nonetheless, in 1907, Schwalbe and Gredig, ${ }^{92}$ writing from Arnold's lab in Heidelberg, described four cases of myelomeningocele and added Arnold's name to the type II malformation, coining the term Arnold-Chiari malformation. They even referred to the cerebellar malformation as Arnold's deformity and the medullary deformity as Chiari's deformity. Twenty-five years later, in 1932, C. J. Van Houweninge Graftidijk reported the first attempt at surgical correction of this deformity, in his thesis for Doctorate in Medicine entitled "Over hydrocephalus." 88 He intended to relieve the obstruction of CSF flow at the level of the deformity by resecting the tongue of redundant tissue or by resecting the bone over the posterior surface of the malformation and incising the underlying dura. His patients, however, died of the effects of the operation or of postoperative complications. $^{88}$

\section{INTRODUCTION OF CHIARI MALFORMATIONS INTO THE ENGLISH LITERATURE}

The interest in these conditions surged in 1935 after Russell and Donald ${ }^{88}$ introduced the notion of Chiari malformations into the English-language literature. They described 10 consecutive infants with Chiari II malformation and used the term Arnold-Chiari malformation

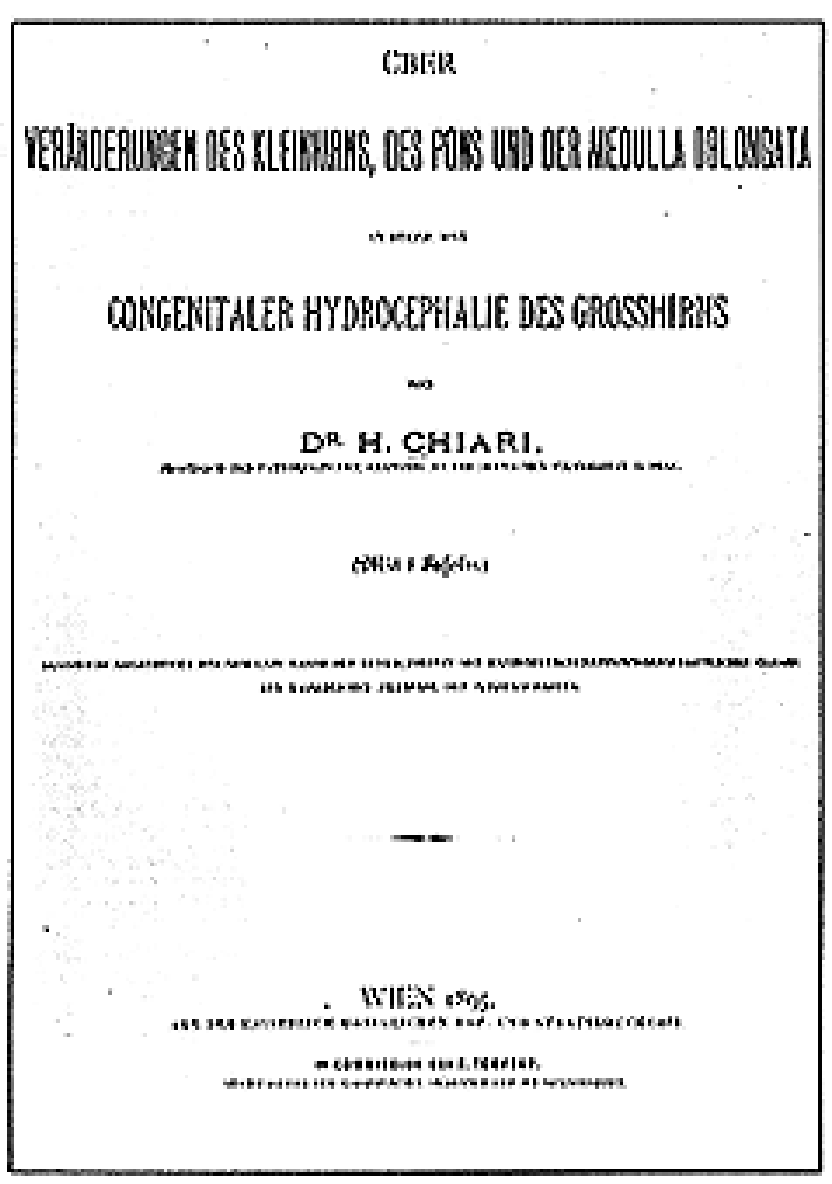

Fig. 2. Title page of Chiari's second paper. Used with permission from De Lotbinière ACJ: Historical considerations, in Anson JA, Benzel EC, Awad IA (eds): Syringomyelia and the Chiari malformations. Neurosurgical Topics. American Association of Neurological Surgeons: Chicago 1997, 1-26.

coined by Schwalbe and Gredig. ${ }^{92}$ Adult cases of Chiari I malformation were not described until 1938, when McConnell and Parker ${ }^{64}$ reported five cases, all with hydrocephalus and neurological symptoms, in whom surgical exploration was performed; an autopsy procedure was performed in three. They used the term "tonsils" to describe the prolapsed cerebellar tissue. The same year, Aring ${ }^{5}$ reported a 20 -year-old man with an adult Chiari malformation but no hydrocephalus. This was the first reported case of adult Chiari malformation in a patient in whom hydrocephalus was not also present. The condition was diagnosed by cerebellar exploration, and the patient died 18 hours later. The cerebellar tonsils reached down to the axis.

In 1940 Gustafson and Oldberg ${ }^{46}$ described another two patients in whom diagnosis was made intraoperatively. In 1941, Walsh, et al., ${ }^{106}$ described another case in which the diagnosis was made intraoperatively, although radiographs had revealed the presence of basilar invagination. Also in 1941, List ${ }^{60}$ described two cases: in one patient (Case 5), the presence of an Arnold-Chiari malformation was suspected preoperatively based on the anomalous foramen magnum and the blockage at the foramen magnum observed on ventriculography; in the patient in Case 
6 , however, the neurological picture was "interpreted as being due to an Arnold Chiari deformity rather than to bony compression" based on blockage demonstrated on myelography. This case was the first report of myelographic diagnosis of Chiari malformation. The same year Adams, et al., ${ }^{2}$ described another case in which preoperative myelography demonstrated a block at the level of C-3: they assumed the lesion was a tumor of the cervical cord, but on surgical exploration a diagnosis of a Chiari malformation was made. Adams, et al., delineated the clinical sydrome and classified the symptoms into five groups: increased ICP, involvement of several of the cranial nerves, compression of the brainstem, compression of the spinal cord, and cerebellar signs, and they described the myelographic appearance of the protruding cerebellar tonsils.

Other reports followed, which were mostly isolated case reports and some small series; ${ }^{3,18,20,43,45,51,58,61,72,95,96}$ however, it was during the 1970 s that the term adult Chiari malformation gained popularity ${ }^{4,11,33,63,69,85,89}$ and large series were published. This trend increased considerably over the following two decades. $8,15,19,32,34,35,44,47,54,59,68,78,81,90,98$

\section{PATHOLOGICAL CLASSIFICATION}

In 1949 Russell $^{87}$ suggested that "it would appear preferable to restrict the use of the term Arnold Chiari malformation to those cases in which the spina bifida type of abnormality is identified" or Chiari II malformation, rather than using it for "any caudal prolongation of the medulla oblongata or of the cerbellum including tonsillar herniation associated with cerebral tumors." Later, she "questioned the existence of a genuine Arnold-Chiari malformation in the absence of spina bifida." 86 This distinction was reemphasized by Peach ${ }^{79}$ in 1965 and became widespread over the following decade.

Debate on the classification of the tonsillar herniations was undertaken more recently in the pathology literature. In 1976 , Friede and Roessmann ${ }^{42}$ reappraised the classification of the Chiari I malformation after reviewing all reported cases of chronic tonsillar herniations at the foramen magnum in the absence of intracranial space-occupying lesions. They believed that "the uncritical propagation of the term 'malformation' for Chiari type I lesions has done much harm to obfuscate the issue of chronic tonsillar herniations in the absence of space-occupying supratentorial lesions." Chiari's descriptions in 1891 and 1896 addressed cerebellar lesions in infants with hydrocephalus. Two concepts were not known at that time: the relation between the flow of CSF and hydrocephalus and the concept of tonsillar herniation induced by increased ICP. It was only during the following decade that the latter concept had been reported by Cushing ${ }^{28}$ and Collier, ${ }^{27}$ and it did not become widely known until Meyer's report ${ }^{66}$ in 1920 on the various herniations, including the subfalcine and transtentorial herniations. According to Friede ${ }^{41} \mathrm{Chi}-$ ari's description of the type I malformation referred mostly to cerebellar pressure cones. Sclerosis of the herniated tonsils might have been the result of the protracted path to death that was common in those days in infantile hydrocephalus. Friede and Roessmann ${ }^{42}$ distinguished between two types of cerebellar herniations: a chronic herniation of the cerebellar tonsils in the absence of space-occupying supratentorial lesions and an adult Arnold-Chiari malformation in which at least one hindbrain deformity is associated with tonsillar herniation. The hindbrain deformities are similar to some of those encountered in the infantile form and would include medullary deformities comparable with those found in the infantile form (typical hump, beak, or kinking of its dorsal portion at the cervicomedullary junction) and an upward course of the cervical rootlets. In contrast to the infantile form, however, the cerebellar tonsils, but not the vermis, herniate through the foramen magnum, although the most caudal portion of the fourth ventricle, particularly the choroid plexus, may herniate, and there is no associated myelomeningocele and spina bifida. Friede and Roessmann supported their proposition by reviewing all the cases reported in the literature for which there was appropriate documentation as well as 13 of their own cases. Twenty-five cases of adult Arnold-Chiari malformation and 39 cases of chronic tonsillar herniation were found. ${ }^{13,25,26,29,38,46,57,75,83,91,99,100,102}$ It is worth mentioning that both groups had associated osseous anomalies and syringomyelia, indicating a possible difference in degree only between the groups. This issue remains unanswered, however.

\section{A Small Posterior Fossa, Craniocephalic Disproportion, and Tonsillar Ectopia}

Perhaps tonsillar herniation can be viewed as a craniocephalic disproportion or disproportion between the container (skull) and the contents. This is confirmed by examples of acquired tonsillar descent. Acquired tonsillar ectopia is seen in various conditions; in some cases the volume of the cranial cavity is reduced, and in others the volume of the intracranial contents is increased. Disorders associated with the former condition include severe craniosynostosis ${ }^{23}$ and lesions that cause calvarial thickening such as Paget disease, ${ }^{36}$ rickets, ${ }^{56}$ and erythroid hyperplasia. ${ }^{84}$ Disorders that cause an increase in the volume of the intracranial contents and induce tonsillar descent are associated with supratentorial tumors ${ }^{77,94}$ and infratentorial mass lesions. ${ }^{93,103}$ The tonsillar herniation resolved after tumor resection. Acute tonsillar herniation is a common finding in cases of rapidly enlarging intracranial processes such as acute brain edema, intracerebral hemorrhage and acute hydrocephalus. Mikulis, et al., ${ }^{67}$ have shown that with increasing patient age there is tonsillar ascent linked to neuronal dropout, volume loss, and brain atrophy.

Similarly, in patients with adult Chiari malformation, recent studies have revealed the presence of a small posterior fossa. Using the posterior fossa ratio method, $\mathrm{Ny}$ land and Krogness ${ }^{73}$ found that the posterior fossa was small in five patients with adult Chiari malformation. Based on examination of lateral skull radiographs, Stovner, et al. ${ }^{97}$ found that the posterior fossa was smaller and shallower in patients with Chiari I malformation than in controls. Badie, et al., ${ }^{8}$ compared the ratio of the posterior fossa with supratentorial volumes on MR images obtained in 20 patients with Chiari I malformation and 20 control patients. The ratio was smaller in the former patients, and those with smaller posterior fossa developed symptoms earlier and were more likely to respond to decompressive surgery. Nishikawa, et al.,11 found a higher volume ratio of the posterior fossa brain compared with that of the posterior fossa cranium. Milhorat, et al., ${ }^{68}$ have also reported 
similar findings, and they concluded that Chiari I malformation is a disorder of the mesoderm leading to a volumetrically small posterior fossa that predisposes patients to hindbrain overcrowding. Experimentally-induced small posterior fossa was also found to lead to tonsillar herniation. ${ }^{62}$

\section{RADIOLOGICAL CRITERIA FOR CHIARI MALFORMATION: THE PRE-MR IMAGING ERA}

Attempts at finding radiological criteria for the Chiari malformations were published mainly in the radiology literature.

Perhaps Baker ${ }^{9}$ was the first to attempt defining criteria for the extent of tonsillar ectopia needed for a diagnosis of the Chiari malformation. He considered, by definition, the cerebellar tonsils to lie in a normal position if the lower border was above a line joining the posterior rim of the foramen magnum and the tip of the clivus on lateral view. He described 28 cases of developmental anomalies found in a pool of 179 patients in whom symptoms and signs were referable to the upper cervical posterior fossa region and who underwent myelography. Of three patients with marked constriction of the foramen magnum, two underwent decompressive surgery and their neurological status improved postoperatively. Herniation of the tonsils down to the arch of C-1 was present in 11 patients, in whom Arnold-Chiari malformation was diagnosed. In the remaining 14 patients myelography demonstrated normal findings except that the cerebellar tonsils were located 2 to 5 $\mathrm{mm}$ below the foramen magnum. The author wrote, "Since there was no obstruction to the free flow of fluid through the foramen magnum it was difficult to justify operative decompression.... However, three such patients with severe intermittent symptoms, which were thought to be due to a ball-valve type of obstruction, were surgically treated." Baker concluded that "these cases represent a mild form of Arnold-Chiari malformation [Chiari type I] and that further observation is necessary to establish the clinical significance of the low grade tonsillar herniation.",9

In 1973 O'Connor, et al., ${ }^{74}$ emphasized the "need to establish the normal location of the tonsils... so that an abnormally low position may be recognized." They studied 100 myelograms, excluding cases of foramen magnum or intracranial mass space-occupying lesions. These studies were obtained in patients with various conditions including disseminated sclerosis, neck or back pain of unknown origin, and motor neuron disease. The tonsils were always above the basion-opisthion line. The authors concluded that "demonstration of the tonsils at the level of and through the foramen magnum is a strong evidence of a Chiari malformation," but they cautioned that "coincidental disease of the central nervous system [with] demonstration of tonsillar herniation..." could confuse the diagnosis.

In 1974 Bloch, et al., ${ }^{16}$ measured the distance of the tonsillar tip from the upper lip of the foramen magnum on the anteroposterior view of myelograms obtained in 60 normal volunteers and 19 patients with Arnold-Chiari malformation. The tonsils ranged from $7 \mathrm{~mm}$ above to $8 \mathrm{~mm}$ below the upper lip in the normal cases, and from $3 \mathrm{~mm}$ above to $25 \mathrm{~mm}$ below the inner rim in patients with Chi- ari malformation. Magnification was not accounted for. They concluded that marked tonsillar herniation can be encountered as an incidental finding.

Computerized tomography with or without injection of intrathecal metrizamide has been used to establish a diagnosis of the Chiari malformation, but there have been no attempts to find definite criteria by which to diagnose adult Chiari malformation. ${ }^{17,31,39,40,49,70}$

\section{RADIOLOGICAL CRITERIA FOR ADULT CHIARI MALFORMATION: THE MR IMAGING ERA}

In 1985, Aboulezz, et al., ${ }^{1}$ used MR imaging to study the position of the cerebellar tonsils in the normal population (82 individuals) and in 13 patients with Chiari malformations (11 with type I and two with type II). In the normal population the position of the tonsils varied from $2.8 \mathrm{~mm}$ below the foramen magnum to $20 \mathrm{~mm}$ above, whereas in patients with Chiari malformations the tonsils were located 5.2 to $17.7 \mathrm{~mm}$ below the foramen magnum and in all cases the tonsils were pointed. The authors concluded that the tonsils may extend up to $3 \mathrm{~mm}$ below the foramen magnum in the normal population, and in patients with Chiari malformation they extend $5 \mathrm{~mm}$ or greater below the foramen magnum.

The following year Barkovich, et al., ${ }^{12}$ compared the MR images obtained in 200 patients with clinical symptoms unrelated to the Chiari I malformation or other cervicocranial anomalies with those obtained in 25 patients with the Chiari I malformation. Patients for whom imaging studies could not clearly be classified into one of these categories were excluded from the study, raising the possibility that some mimimally symptomatic or as yet asymptomatic patients were missed. The tonsils were located from $8 \mathrm{~mm}$ above to $5 \mathrm{~mm}$ below the foramen magnum in the controls and from 3 to $29 \mathrm{~mm}$ below the foramen magnum in patients with Chiari malformation. Peglike tonsils were found in both groups. Narrowing or complete effacement of the CSF spaces of the foramen magnum and cisterna magna were documented in all patients with more than $1 \mathrm{~mm}$ tonsillar ectopia. The authors concluded that, in terms of the most accurate diagnosis, a herniation $2 \mathrm{~mm}$ below the foramen magnum should be the cutoff because no symptomatic patient had less than 3-mm herniation and only one asymptomatic patient had more than 3-mm ectopia.

In 1988 Ishikawa, et al., ${ }^{52}$ studied 50 control patients and found that the cerebellar tonsils were always located above the line of the foramen magnum.

In 1992 Elster and Chen ${ }^{37}$ found that Chiari I malformation was documented in $0.56 \%$ of patients who underwent MR imaging in a tertiary care center and in another $0.16 \%$ this diagnosis was also possible. A 5-mm cutoff for one tonsil, or 3 to $5 \mathrm{~mm}$ cutoff for both tonsils was used as the diagnostic criterion. A female preponderence (2:1) was reported for the first time. In $12 \%$ only subjective findings were demonstrated, and $31 \%(0.17 \%$ of the total population examined) were asymptomatic (ectopia from 5-12 mm). The authors concluded that a "careful clinical assessment remains the cornerstone for proper diagnosis and management."

The same year Mikulis, et al., ${ }^{67}$ studied how tonsillar 
position varies with patient age in 220 patients (age range 5 months -89 years). They found that the cerebellar tonsils ascend with increasing age and suggested the following criteria for ectopia: first decade, $6 \mathrm{~mm}$ below the foramen magnum; second to third decades, $5 \mathrm{~mm}$; fourth to eighth decades, $4 \mathrm{~mm}$; and ninth decade, $3 \mathrm{~mm}$ below the foramen magnum. These criteria were based on the distance greater than two standard deviations from the normal range for each decade.

In 1998 Iskandar, et al., ${ }^{53}$ described five children with syringohydromyelia in whom clinical and radiological resolution were demonstrated after posterior fossa decompression. None of the patients had hindbrain herniation. Their course was similar to that of patients with Chiari malformation. In cases in which preoperative cine-MR imaging was performed, decreased or normal-to-decreased flow was demonstrated. On review of the published MR images, the cerebellar tonsils were found at the level of the foramen magnum (Fig. 3). Three years later, Tubbs, et al., ${ }^{105}$ added a sixth case and analyzed various radiological indices, finding that the contents of the posterior fossa were indeed compromised in these patients, even in the absence of tonsillar ectopia, and that the obices were located more than two standard deviations below normal. "Chiari zero malformation" was the name they chose to characterize the disorder.

In their seminal paper of 1999, Milhorat, et al., ${ }^{68}$ studied 364 symptomatic patients with Chiari I malformation. They found that in $32(9 \%)$ of the 364 symptomatic patients tonsillar ectopia of less than $5 \mathrm{~mm}$ was demonstrated, but compression of the CSF spaces posterior and lateral to the cerebellum was present in all cases. In fact the tonsils were at the level of the foramen magnum in the illustrative case they presented (Fig. 4).

In 2000 Meadows, et al., ${ }^{65}$ published a review of 22,591 patients in whom MR imaging was performed. Tonsillar herniation extending more than $5 \mathrm{~mm}$ below the foramen magnum was found in $0.77 \%$. Fourteen percent of those patients were asymptomatic (with $7-25 \mathrm{~mm}$ of ectopia) and $25 \%$ of those had peglike tonsils. The authors concluded that "isolated tonsillar herniation is of limited

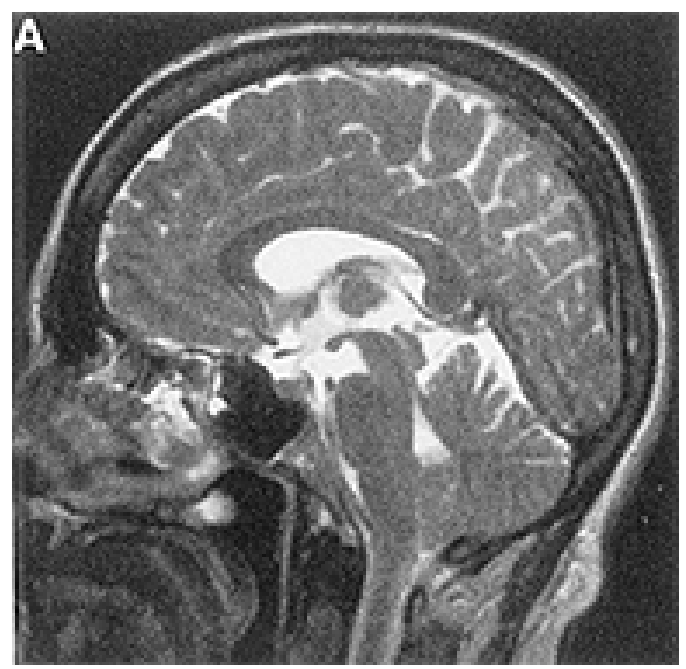

Fig. 4. The illustrative case of adult Chiari malformation reported by Milhorat, et al., in which the tonsillar herniation extended less than $5 \mathrm{~mm}$ below the foramen magnum. In fact the tonsils are at the level of the foramen magnum. The patient had typical Chiari symptoms that resolved immediately postoperatively. Neurosurgery 44:1005-1017, 1999.

prognostic utility, and should be considered in the context of all available clinical and imaging data....".

Based on the review of all these papers the following remarks can be made. 1) Radiologically significant tonsillar ectopia may be completely asymptomatic. 2) There are patients in whom the tonsillar herniation extends less than $5 \mathrm{~mm}$ from the foramen magnum, whose clinical behavior is similar to the remainder of the Chiari population, including even those with radiological evidence of syringohydromyelia.

These findings concur with the conclusion of Meadows, et al. ${ }^{65}$ in that the radiological criteria for the extent of tonsillar herniation are not absolute and should be considered within the clinicopathological context.

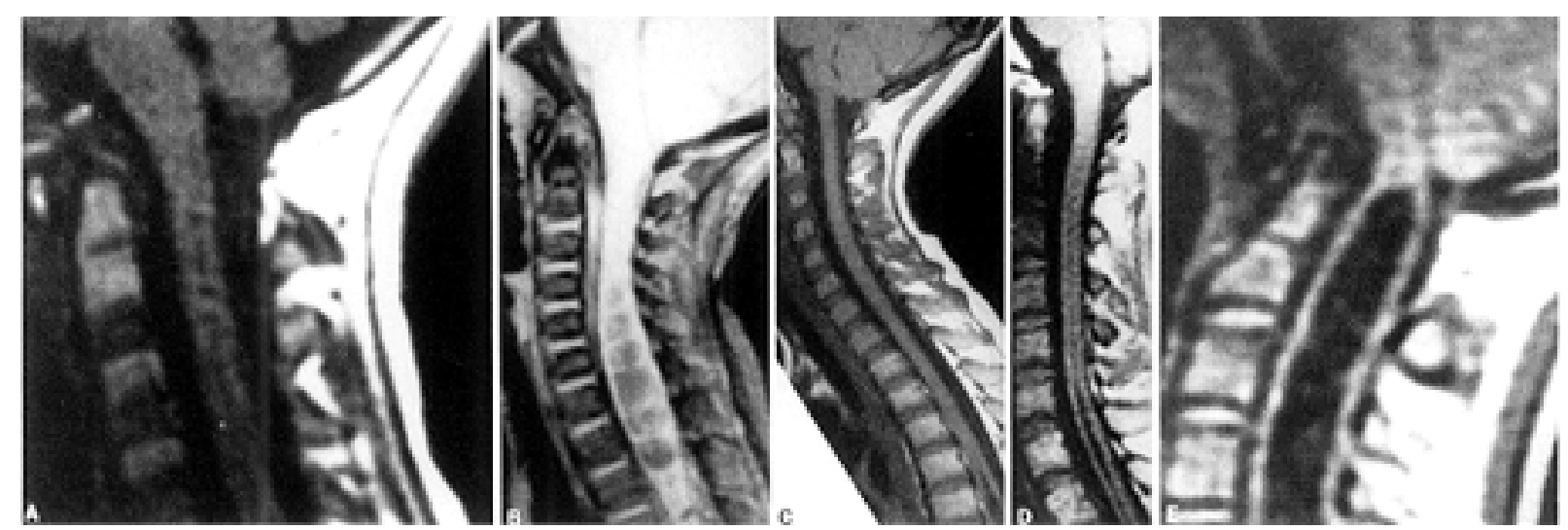

Fig. 3. Magnetic resonance images obtained in the five cases of Chiari zero malformations reported by Iskandar, et al. The tonsils are at the level of the formen magnum. All five patients had syringomyelia that resolved after posterior fossa decompression. Used with permission from Iskandar, et al:The resolution of syringohydromyelia without hindbrain herniation after posterior fossa decompression. J Neurosurg 89:212-216, 1998. 


\section{DYNAMIC MR IMAGING STUDIES OF ADULT CHIARI MALFORMATION}

The use of dynamic MR imaging studies to diagnose CSF flow obstruction in patients with Chiari malformation was first reported in 1991 by Tominaga, et al. ${ }^{104}$ They described CSF flow obstruction at the level of the foramen magnum in a patient with basilar impression accompanied by Chiari malformation and its resolution after transoral decompressive surgery. In 1994 Oldfield, et al. ${ }^{76}$ reported three patients with Chiari malformation in whom cine-MR studies were performed. Later the same year Armonda, et al., ${ }^{6}$ reported the first series of patients with Chiari malformation who underwent cine-MR imaging. Other studies followed in which the authors described the characteristics of the Chiari malformation on dynamic MR imaging, ${ }^{14,48,50,82,101,107}$ however, there was no attempt to define criteria that would clearly delineate the normal control individuals from symptomatic patients.

\section{CONCLUSIONS}

Perhaps it is the opening statement written by Ball and Crone ${ }^{10}$ in their editorial that seems appropriate as a concluding remark: "Ever since the initial postmortem description by Chiari in 1891 of the group of malformations that bears his name, it seems there have always been more questions on this subject than answers." As we have seen, the definition of the adult Chiari malformation has varied with the evolution of our neurodiagnostic capabilities and knowledge of physiopathology. There is no single test that allows a clear-cut distinction between clinically significant tonsillar ectopia and incidental tonsillar descent. With the fluidity of the definition of the adult Chiari malformation, as well as the increasing number of asymptomatic patients with significant radiological tonsillar herniation, it is the clinical judgment of the physicians evaluating this disorder that is of the utmost importance to avoid the therapeutic extremes of pursuing unnecessary surgery or withholding necessary treatment from patients.

\section{Acknowledgments}

The author would like to acknowledge Mrs. Alexis Ferencz for her assistance in preparing this manuscript. The author is also grateful for his Chiari patients, especially JR and TH, who got him interested in the study of the adult Arnold-Chiari malformation.

\section{References}

1. Aboulezz AO, Sartor K, Geyer CA, et al: Position of cerebellar tonsils in the normal population and in patients with Chiari malformation: a quantitative approach to MR imaging. J Comput Assist Tomogr 9:1033-1036, 1985

2. Adams RD, Schatzki R, Scoville WB: The Arnold-Chiari malformation. Diagnosis, demonstration by intraspinal lipiodal and successful surgical treatment. N Engl J Med 225:125-131, 1941

3. Appleby A, Foster JB, Hankinson J, et al: The diagnosis and management of the Chiari anomalies in adult life. Brain 91: 131-140, 1968

4. Archer CR, Horenstein S, Sundaram M: The Arnold-Chiari malformation presenting in adult life. A report of thirteen cases and a review of the literature. J. Chronic Dis 30:369-382, 1977

5. Aring CD: Cerebellar syndrome in an adult with malformation of the cerebellum and brain stem (Arnold-Chiari deformity), with a note on the occurrence of "torpedos" in the cerebellum. J Neurol Psychiatry 1:100-109, 1938

6. Armonda RA, Citrin CM, Foley KT, et al: Quantitative cinemode magnetic resonance imaging of Chiari I malformations: an analysis of cerebrospinal fluid dynamics. Neurosurgery 35: 214-224, 1994

7. Arnold J: Myelocyste, Transposition von Gewebskeimen und Sympodie. Beitr Path Anat 16:1-28, 1894

8. Badie B, Mendoza D, Batzdorf U: Posterior fossa volume and response to suboccipital decompression in patients with Chiari I malformation. Neurosurgery 37:214-218, 1995

9. Baker HL Jr: Myelographic examination of the posterior fossa with positive contrast medium. Radiology 81:791-801, 1963

10. Ball WS Jr, Crone KR: Chiari I Malformation: from Dr. Chiari to MR imaging. Radiology 195:602-604, 1995

11. Banerji NK, Millar JH: Chiari malformation presenting in adult life. Its relationship to syringomyelia. Brain 97:157-168, 1974

12. Barkovich AJ, Wippold JF, Sherman JL, et al: Significance of cerebellar tonsillar position on MR. AJNR 7:795-799, 1986

13. Bedi SS: Arnold-Chiari malformation presenting as syringomyelia. Ann Phys Med 10:16-17, 1969

14. Bhadelia RA, Bogdan AR, Wolpert SM, et al: Cerebrospinal fluid flow waveforms: analysis in patients with Chiari I malformation by means of gated phase-contrast MR imaging velocity measurements. Radiology 196:195-202, 1995

15. Bindal AK, Dunsker SB, Tew JM Jr: Chiari I malformation: classification and management. Neurosurgery 37:1069-1074, 1995

16. Bloch S, Van Rensburg MJ, Danziger J: The Arnold-Chiari malformation. Clin Radiol 25:335-341, 1974

17. Bonafé A, Manelfe C, Espagno J, et al: Evaluation of syringomyelia with metrizamide computed tomographic myelography. J Comput Assist Tomogr 4:797-802, 1980

18. Bucy PC, Lichtenstein BW: Arnold-Chiari deformity in an adult without obvious cause. J Neurosurg 2:245-250, 1945

19. Cahan LD, Bentson JR: Considerations in the diagnosis and treatment of syringomyelia and the Chiari malformation. J Neurosurg 57:24-31, 1982

20. Carmel PW, Markesbery WR: Arnold-Chiari malformation in an elderly woman. Arch Neurol 21:258-262, 1969

21. Chiari H: Uber die Veränderungen des Kleinhirns, der Pons und der Medulla oblongata in Folge von congenitaler Hydrocephalie des Grosshirns. Denkschr Akad Wissensch Math Naturw Cl 63:71-116, 1895

22. Chiari H: Uber Veränderungen des Kleinhirns infolge von Hydrocephalie des Grosshirns. Dtsch Med Wschr 17:1172-1175, 1891

23. Cinalli G, Chumas P, Arnaud E, et al: Occipital remodeling and suboccipital decompression in severe craniosynostosis associated with tonsillar herniation. Neurosurgery 42:66-73, 1998

24. Cleland J: Contribution to the study of spina bifida, encepahlocele, and anencephalus. J Anat Physiol 17:257-292, 1883

25. Cogan DG, Barrows LJ: Platybasia and the Arnold-Chiari malformation. Arch Ophthalmol 52:13-29, 1954

26. Colclough JA: Simulation of herniated cervical disc by the Arnold-Chiari deformity. Presentation of two cases in adults. Surgery 28:874-880, 1950

27. Collier J: The false localising signs of intracranial tumor. Brain 27:490-508, 1904

28. Cushing H: Some experimental and clinical observations concerning states of increased intracranial tension. Am J Med Sci 124:377-400, 1902

29. Custis DL, Verbrugghen A: Basilar impression resembling cerebellar tumor. Arch Neurol Psychiatry 52:412-415, 1944

30. de Lotbinière ACJ: Historical considerations, in Anson JA, Benzel EC, Awad IA (eds): Syringomyelia and the Chiari Malformations. Neurosurgical Topics. Park Ridge, IL: American Association of Neurological Surgeons, 1997, pp 1-26 
31. Di Lorenzo N, Bozzao L, Antonelli M, et al: Arnold-Chiari malformation detected by unenhanced multiplanar CT scan. Surg Neurol 16:340-345, 1981

32. Di Lorenzo N, Palma L, Palatinsky E, et al: "Conservative" cranio-cervical decompression in the treatment of syringomyelia-Chiari I complex. A prospective study of 20 adult cases. Spine 20:2479-2483, 1995

33. Dobkin BH: The adult Chiari malformation. Bull Los Angeles Neurol Soc 42:23-27, 1977

34. Dyste GN, Menezes AH, VanGilder JC: Symptomatic Chiari malformations. An analysis of presentation, management, and long-term outcome. J Neurosurg 71:159-168, 1989

35. Eisenstat DD, Bernstein M, Fleming JF, et al: Chiari malformation in adults: a review of 40 cases. Can J Neurol Sci 13: 221-228, 1986

36. Elisevich K, Fontaine S, Bertrand G: Syringomyelia as a complication of Paget's disease. Case report. J Neurosurg 67: 611-613, 1987

37. Elster AD, Chen MY: Chiari I malformations: clinical and radiologic reappraisal. Radiology 183:347-353, 1992

38. Epstein BS: Pantopaque myelography in the diagnosis of the Arnold-Chiari malformation without concomitant skeletal or central nervous system defects. Am J Roentgenol 59:359-364, 1948

39. Finn S, Rieux D, Fressinaud P, et al: Chiari Type I malformation with hydromyelia: findings at computerized metrizamide ventriculomyelography. Surg Neurol 12:227-229, 1979

40. Forbes WS, Isherwood I: Computed tomography in syringomyelia and the associated Arnold-Chiari Type I malformation. Neuroradiology 15:73-78, 1978

41. Friede RL: Developmental Neuropathology, ed 2. Berlin: Springer-Verlag, 1989

42. Friede RL, Roessmann U: Chronic tonsillar herniation: an attempt at classifying chronic herniations at the foramen magnum. Acta Neuropathol 34:219-235, 1976

43. Gardner WJ, Goodall RJ: The surgical treatment of ArnoldChiari malformation in adults. J Neurosurg 7:199-206, 1950

44. Goel A, Bhatjiwale M, Desai K: Basilar invagination: a study based on 190 surgically treated patients. J Neurosurg 88: 962-968, 1998

45. Golding DNJ: Cerebellar ectopia presenting in adult life. $\mathbf{B r}$ Med J 2:119, 1969

46. Gustafson WA, Oldberg E: Neurologic significance of platybasia. Arch Neurol Psychiatry 44:1184-1198, 1940

47. Guyotat J, Bret P, Jouanneau E, et al: Syringomyelia associated with Type I Chiari malformation. A 21-year retrospective study on 75 cases treated by foramen magnum decompression with a special emphasis on the value of tonsils resection. Acta Neurochir 140:745-754, 1998

48. Heiss JD, Patronas N, DeVroom HL, et al: Elucidating the pathophysiology of syringomyelia. J Neurosurg 91:553-562, 1999

49. Hochman MS, Kobetz SA, Sneider SE, et al: Adult Arnold-Chiari malformation type I demonstrated by CT metrizamide myelography. Surg Neurol 16:467-468, 1981

50. Hofmann E, Warmuth-Metz M, Bendszus M, et al: Phase-contrast MR imaging of the cervical CSF and spinal cord: volumetric motion analysis in patients with Chiari I malformation. AJNR 21:151-158, 2000

51. Hurteau EF: Arnold-Chiari malformation. J Neurosurg 7: 282-284, 1950

52. Ishikawa M, Kikuchi H, Fujisawa I, et al: Tonsillar herniation on magnetic resonance imaging. Neurosurgery 22:77-81, 1988

53. Iskandar BJ, Hedlund GL, Grabb PA, et al: The resolution of syringohydromyelia without hindbrain herniation after posterior fossa decompression. J Neurosurg 89:212-216, 1998

54. Klekamp J, Batzdorf U, Samii M, et al: The surgical treatment of Chiari I malformation. Acta Neurochir 138:788-801, 1996

55. Koehler PJ: Chiari's description of cerebellar ectopy (1891). With a summary of Cleland's and Arnold's contributions and some early observations on neural-tube defects. J Neurosurg 75:823-826, 1991

56. Kuether TA, Piatt JH: Chiari malformation associated with vitamin D-resistant rickets: case report. Neurosurgery 42: 1168-1171, 1998

57. Labsan HF, Proctor LD: Syringomyelia associated with Arnold-Chiari malformation. Henry Ford Hosp Bull 8: 157-162, 1960

58. Larson SJ, Sances A Jr, Baker JB, et al: Herniated cerebellar tonsils and cough syncope. J Neurosurg 40:524-528, 1974

59. Levy WJ, Mason L, Hahn JF: Chiari malformation presenting in adults: a surgical experience in 127 cases. Neurosurgery 12: 377-390, 1983

60. List CF: Neurologic syndromes accompanying developmental anomalies of occipital bone, atlas, and axis. Arch Neurol 45: 577-616, 1941

61. Malis LI, Cohen I, Gross SW: Arnold-Chiari malformation. Arch Surg 63:783-798, 1951

62. Marin-Padilla M, Marin-Padilla TM: Morphogenesis of experimentally induced Arnold-Chiari malformation. J Neurol Sci 50:29-55, 1981

63. Maroun FB, Jacob JC, Mangan M: The Chiari malformation in adults. Can J Neurol Sci 2:115-120, 1975

64. McConnell AA, Parker HL: A deformity of the hind-brain associated with internal hydrocephalus. Its relation to the $\mathrm{Ar}$ nold-Chiari malformation. Brain 61:415-429, 1938

65. Meadows J, Kraut M, Guarnieri M, et al: Asymptomatic Chiari Type I malformations identified on magnetic resonance imaging. J Neurosurg 92:920-926, 2000

66. Meyer A: Herniation of the brain. Arch Neurol Psychiatry 4: $387-400,1920$

67. Mikulis DJ, Diaz O, Egglin TK, et al: Variance of the position of the cerebellar tonsils with age: preliminary report. Radiology 183:725-728, 1992

68. Milhorat TH, Chou MW, Trinidad EM, et al: Chiari I malformation redefined: clinical and radiographic findings for 364 symptomatic patients. Neurosurgery 44:1005-1017, 1999

69. Mohr PD, Strang FA, Sambrook MA, et al: The clinical and surgical feature in 40 patients with primary cerebellar ectopia (adult Chiari malformation). Q J Med 46:85-96, 1977

70. Naidich TP, Pudlowski RM, Naidich JB, et al: Computed tomographic signs of the Chiari II malformation. Part I: skull and dural partitions. Radiology 134:65-71, 1980

71. Nishikawa M, Sakamoto H, Hakuba A, et al: Pathogenesis of Chiari malformation: a morphometric study of the posterior cranial fossa. J Neurosurg 86:40-47, 1997

72. Norton T, Pawl RP: The Arnold-Chiari deformity in elderly patients: diagnosis and treatment. Neurochirurgia 15:153-159, 1972

73. Nyland H, Krogness KG: Size of posterior fossa in Chiari type I malformation in adults. Acta Neurochir 40:233-242, 1978

74. O'Connor S, du Boulay G, Logue V: The normal position of the cerebellar tonsils as demonstrated by myelography. J Neurosurg 39:388-389, 1973

75. Ogryzlo MA: The Arnold-Chiari malformation. Arch Neurol Psychiatry 48:30-46, 1942

76. Oldfield EH, Muraszko K, Shawker TH, et al: Pathophysiology of syringomyelia associated with Chiari I malformation of the cerebellar tonsils. Implications for diagnosis and treatment. $\mathbf{J}$ Neurosurg 80:3-15, 1994

77. Onesti ST, Ashkenazi E, Miller AM, et al: Resolution of acquired tonsillar herniation after resection of supratentorial meningioma. Case illustration. J Neurosurg 86:572, 1997

78. Paul KS, Lye RH, Strang FA, et al: Arnold-Chiari malformation. Review of 71 cases. J Neurosurg 58:183-187, 1983

79. Peach B: Arnold-Chiari malformation. Anatomic features of 20 cases. Arch Neurol 12:613-621, 1965

80. Pearce JM: Arnold Chiari, or "Cruveilhier Cleland Chiari" malformation. J Neurol Neurosurg Psychiatry 68:13, 2000

81. Pillay PK, Awad IA, Little JR, et al: Symptomatic Chiari mal- 
formation in adults: a new classification based on magnetic resonance imaging with clinical and prognostic significance. Neurosurgery 28:639-645, 1991

82. Pujol J, Roig C, Capdevila A, et al: Motion of the cerebellar tonsils in Chiari type I malformation studied by cine phasecontrast MRI. Neurology 45:1746-1753, 1995

83. Ray BS: Platybasia with involvement of the central nervous system. Ann Surg 116:231-250, 1942

84. Rengachary SS, Blount J, Heros D, et al: Craniocephalic disproportion with increased intracranial pressure and brain herniation: a new clinical syndrome in anemic patients: report of two cases. Neurosurgery 41:297-304, 1997

85. Rhoton AL Jr: Microsurgery of Arnold-Chiari malformation in adults with and without hydromyelia. J Neurosurg 45: 473-483, 1976

86. Russell DS: Hydrocephalus. Res Publ Assoc Res Nerv Ment Dis 34:160-175, 1954

87. Russell DS: Observations on the Pathology of Hydrocephalus. London: HM Stationary Office, 1949

88. Russell DS, Donald C: The mechanism of internal hydrocephalus in spina bifida. Brain 58:203-215, 1935

89. Saez RJ, Onofrio BM, Yanagihara T: Experience with Arnold-Chiari malformation, 1960 to 1970. J Neurosurg 45: 416-422, 1976

90. Sawin PD, Menezes AH: Basilar invagination in osteogenesis imperfecta and related osteochondrodysplasias: medical and surgical management. J Neurosurg 86:950-960, 1997

91. Schuster DP: The Arnold-Chiari malformation. Dis Nerv Syst 15:264-267, 1954

92. Schwalbe E, Gredig M: Ueber Entwicklungstströrungen des Kleihirns, Hirnstamms und Halsmarks bei Spina bifida (Arnold'sche und Chiari'sche Missbildung). Beitr Path Anat 40:132-194, 1907

93. Sgaramella E, Perria C: Regression of syringomyelia after removal of a posterior fossa epidermoid tumor. Br J Neurosurg 10:409-411, 1996

94. Sheehan JM, Jane JA Sr: Resolution of tonsillar herniation and syringomyelia after supratentorial tumor resection: case report and review of the literature. Neurosurgery 47:233-235, 2000

95. Smith J, Ridley A: Cerebellar ectopia presenting in adult life. Br Med J 1:353-355, 1969

96. Spillane JD, Pallis C, Jones AM: Developmental abnormalities in the region of the foramen magnum. Brain 80:11-48, 1957
97. Stovner LJ, Bergan U, Nilsen G, et al: Posterior cranial fossa dimensions in the Chiari I malformation: relation to pathogenesis and clinical presentation. Neuroradiology 35:113-118, 1993

98. Stovner LJ, Rinck P: Syringomyelia in Chiari malformation: relation to extent of cerebellar tissue herniation. Neurosurgery 31:913-917, 1992

99. Swanson HS, Fincher EF: Arnold-Chiari deformity without bony anomalies. J Neurosurg 6:314-319, 1949

100. Teng P, Papatheodorou C: Arnold-Chiari malformation with normal spine and cranium. Arch Neurol 12:622-624, 1965

101. Terae S, Miyasaka K, Abe S, et al: Increased pulsatile movement of the hindbrain in syringomyelia associated with the Chiari malformation: cine-MRI with presaturation bolus tracking. Neuroradiology 36:125-129, 1994

102. Tobin W, Sencer W: Neurological management of congenital malformations of the brain stem and upper cervical spinal cord. J Mt Sinai Hosp 30:503-506, 1963

103. Tokime T, Okamoto S, Yamagata S, et al: Syringomyelia associated with a posterior fossa cyst. Illustration of two cases. $\mathbf{J}$ Neurosurg 86:907, 1997

104. Tominaga T, Koshu K, Ogawa A, et al: Transoral decompression evaluated by cine-mode magnetic resonance imaging: A case of basilar impression accompanied by Chiari malformation. Neurosurgery 28:883-885, 1991

105. Tubbs RS, Elton S, Grabb P, et al: Analysis of the posterior fossa in children with the Chiari 0 malformation. Neurosurgery 48:1050-1055, 2001

106. Walsh MN, Camp JD, Craig WM: Basilar invagination of the skull (so-called platybasia): report of a case with operation. Mayo Clin Proc 16:449-452, 1941

107. Wolpert SM, Bhadelia RA, Bogdan AR, et al: Chiari I malformations: assessment with phase-contrast velocity MR. AJNR 15:1299-1308, 1994

Manuscript received May 25, 2001.

Accepted in final form June 11, 2001.

Address reprint requests to: Ghassan K. Bejjani, M.D., 200

Lothrop Street, Suite 5C, Pittsburgh, Pennsylvania 15213. email: bejjanigk@msx.upmc.edu. 